\title{
As ações físicas de Stanislávski na poética do ator contemporâneo
}

\author{
VÍTOR LEMOS
}

This article contemplates fundamental questions that support the postdoctoral project The character as exercise of difference: perspectives for the physical actions of Stanis/avski, which I am developing at the University of Lisbon (Center for Theater Studies). The study recognizes in the Russian "system" responses to one of the most complex longings of the contemporary actor: to make the character, even in a dramatic context, an exercise of subjectivity. Some fundamental elements proposed by Constantin Stanislavski are commented and revised from contemporary thinking as "baits" for the experience: a psychophysical state produced by the ambivalent tension between, on the one hand, the attention of the actor to the fulfilment of a score of actions and, on the other, what is produced in him by the subjectifying forces that cross this same score.

PHYSICAL ACTIONS / EXPERIENCE / MODES OF SUBJECTIVATION / POETICS OF PERFORMANCE /

Um aspecto importante da atuação contemporânea está localizado em sua abertura para as inúmeras possibilidades expressivas resultantes da tensão ambivalente entre os polos referenciais e autorreferenciais da criação do ator. $O$ termo «ambivalência» indica circulação, não fixidez em possibilidades estanques, não pertencimento nem a uma nem à outra polaridade, ainda que pertença a uma e à outra, simultaneamente. Para que possa habitar esta zona de indeterminação situada «entre» as instâncias teatral e performativa, o ator deve abandonar noções sólidas e fechadas de identidade - tanto para a personagem ficcional, quanto para si - o que torna a atuação, mesmo no ambiente dramático, uma possibilidade de experimentação de diferentes modos de ser.

Ao longo dos últimos trinta anos de exercício profissional como encenador e formador de atores, venho integrando o grupo daqueles que verificam nas ações físicas de Stanislávski caminhos para a realização desse projeto. Não há qualquer dúvida de que a criação artística, em estreita 
sintonia com manifestações vitais, levou o artista russo ao enfrentamento de problemas complexos que se desdobram dessa tensão entre a ficcionalidade da cena e a sua condição de acontecimento. No entanto, a sua permanente abertura para o novo, os agenciamentos específicos dos contextos em que realizou a pesquisa e os diversos ruídos que encontramos na sua transmissão ${ }^{1}$ sugerem aos pesquisadores de hoje uma postura menos servil a uma suposta origem do material.

Explorar o que a tradição chama de «sistema» ou «método» de Stanislávski significa investir numa prática «efêmera e cambiante» (Piccon-Vallin, 2013: 15), ou num «work in progress» (Vássina, 2013: 37) a partir do qual cada artista pode e deve recriar seus próprios processos. ${ }^{2}$ O que segue, portanto, é uma exposição panorâmica do modo como eu venho me apropriando - seja em sala de aula ou em ensaios - de alguns elementos fundamentais do «sistema» a fim de estruturar possibilidades para o ator contemporâneo fazer de sua criação, no ambiente dramático, um processo de subjetivação.

Começo pelos efeitos que a estreia de A gaivota (1898), exatos quarenta anos antes da morte de Stanislávski, trouxe para a sua trajetória artística e, consequentemente, para a do teatro moderno e contemporâneo. O rompimento com a ação dramática rígida promovido por Tchekhov faz com que as suas personagens não resumam a sua razão de ser no discurso explícito. Mais do que isso, ele denuncia a fragilidade do que é dito em cena sem a devida manifestação do que não é dito. Este universo pulsante, invisível e silencioso nos é apresentado em Preparação do Ator no

1 Comento rapidamente algumas questões importantes de serem consideradas acerca da transmissão do legado de Stanislávski: se por um lado, a variedade de artistas que testemunharam sua pesquisa - como atores, alunos, assistentes, discípulos diretos, etc. - prestaram um importante serviço ao teatro difundindo suas práticas pelo território soviético e além de suas fronteiras, por outro, muitos deles não acompanharam a continuidade da investigação até 1938, ano de sua morte. Este facto acarretou a divulgação, através de publicações, cursos e ensaios, de procedimentos identificados como «sistema de Stanislavski», porém cercados de incompreensões, oportunismos, e/ou fidelidade a perspectivas que já haviam sido ou viriam a ser modificadas pelo seu criador. Esses ruídos se agravam ainda mais com as traduções realizadas diretamente do inglês e com a interferência dos editores estadunidenses através de cortes arbitrários em muitos de seus escritos, além da ação da censura soviética, que considerava alguns termos ali adotados como «místicos»e, portanto, hostis aos interesses da revolução. Este contexto político fez com que grande parte do arquivo de Stanislávski só fosse conhecido, estudado e divulgado com o final do regime.

Por esse o motivo, as palavras «método» e «sistema» serão apresentadas sempre entre aspas. 
seu processo criador de vivência das emoções [diário de um discípulo] ${ }^{3}$ como um projeto «exclusivo e prioritário» de criação (no palco) da vida «nas suas manifestações exteriores» e «interior da pessoa representada»a partir dos «elementos orgânicos» oferecidos pela «alma» do artista (Stanislávski, 2018: 42).

Uma ideia de sujeito separa o «pensamento» do «corpo», fazendo do primeiro a expressão de uma intimidade, de uma unidade, de uma essência, enquanto faz do segundo a revelação do «universo exterior», associado às aparências. Palavras como «vida/vivência/organicidade», «emoção», «interno/interior», «alma/espírito» se misturam a outras não menos comuns na literatura stanislavskiana, como «sentimento», «emoção», «profundidade», etc. Neste contexto, o vocabulário destacado pode remeter a um desejo de Stanislávski em privilegiar uma verdade transcendental do ator, da qual o corpo não participa. Muitos rejeitaram e rejeitam o seu nome por conta dessa leitura essencialista do «sistema». No entanto, o mesmo vocabulário, visto a partir da perspectiva de atuação aqui contemplada, remete a uma tentativa do artista russo de nomear, com os recursos do seu tempo, os aspectos autorreferenciais da atuação que ali estavam sendo elaborados. Uma vez alinhados os termos «ação externa» e «ação interna» às noções de «referencialidade»e «autorreferencialidade», respectivamente, podemos reconhecer no legado de Stanislávski um conjunto de respostas ao mesmo ambiente complexo que desafia os atores contemporâneos.

Os esforços de Michele Almeida Zaltron para encontrar um sentido aproximado em língua portuguesa para as palavras perejivánie e voplochtchênie, que juntas resumem o que seria o «trabalho do ator sobre si mesmo» ${ }^{4}$, reforçam esta minha proposição. Dispenso a abordagem das várias opções de tradução oferecidas pela investigadora a partir de diferentes léxicos: o que interessa destacar aqui é o sentido dado à perejivánie (que na publicação portuguesa é traduzida por «vivência das emoções») como processos que envolvem um sujeito e sua relação dinâmica com «o seu entorno, com o mundo, sendo parte inseparável de

3 Esta recente publicação do Teatro D. Maria II (Lisboa) em parceria com a editora Bicho-do- Mato é a primeira tradução feita diretamento do russo para o português da mais conhecida obra de Stanislávski. Anteriormente, havia a publicação brasileira da Editora Civilização Brasileira, A preparação do ator, cuja tradução foi indireta, feita do inglês a partir da publicação norte-americana, An actor prepares.

4 O «trabalho do ator sobre si mesmo» nomeia o conjunto de princípios que acompanhou Stanislávski durante todo o seu percurso artístico e pedagógico. Não por acaso, esta ideia integra o título escolhido pelo artista para a publicação que reuniu seus escritos sobre os processos criadores do ator. 
sua própria existência humana» (Zaltran, 2016: 26-27) - e o sentido de «encarnação» dado à voplochtchênie. Se o ato criador, para Stanislávski, encontra-se na fusão da perejivánie com a voplochtchênie, de modo que uma não possa existir sem a outra, podemos concluir que a sua busca é por um corpo-ator que, mesmo ao executar ações figurativas, encontra-se dinamizado por fluxos relacionais. Esta hipótese reforça a desconfiança de muitos pesquisadores em relação à ideia defendida pela tradição da existência de dois Stanislávski(s): um primeiro, que entendeu o ator a partir de instâncias separadas e perfeitamente definidas, correspondentes, de um lado, ao que seria o externo/físico/corporal, e de outro, ao interno/espiritual/emocional - e um segundo, o Stanislávski das ações físicas, quando estaria desfeita a perspectiva cartesiana para o sujeito-ator. ${ }^{5}$

Outro termo fundamental e profundamente ligado à perejivánie, igualmente incompreendido e difundido equivocadamente, é tchúvstvo. Frequentemente traduzido como «sentimento», «paixão», «emoção», ele acabou sendo confundido com «sentimentalismo», com uma emoção a ser encontrada pelo ator em si mesmo, a partir de um pensamento autônomo ao corpo, muitas vezes orientado por preconcepções e automatismos a respeito da personagem, da cena, da vida, dele mesmo e do outro. Zaltron apresenta a noção de tchúvstvo como a nossa capacidade de reagir afetivamente à percepção do que nos cerca. Uma vez que o meio agencia inúmeras influências, Zaltron afirmará que a aplicação da palavra tchúvstvo pelo «sistema» só estará compreendida quando vista pelo «âmbito dos sentidos e das sensações. Melhor ainda, no sentido amplo da experiência e das percepções» (idem: 65-66).

$\mathrm{O}$ «trabalho do ator sobre si mesmo» resgata para o teatro a força criativa e viva da natureza, facilmente sequestrada pela situação ficcional da cena. $\mathrm{O}$ «natural» não diz respeito a uma origem, a uma identidade, a uma essência, mas às intensidades produzidas por relações de força. As concepções de corpo oferecidas por Deleuze a partir de Artaud e Espinoza tornam-se imprescindíveis na compreensão desse ator «natural». O corpo aqui deve ser entendido como efeito de forças interativas,

5 Análises comparativas entre as edições estadunidenses das obras de Stanislávski e seus originais apontam para certas escolhas, realizadas pelos editores e tradutora, que conduziriam o leitor à ideia de que o «sistema» privilegiaria os aspectos emocionais e psicológicos da personagem aos físicos (ideia difundida no Ocidente). Quanto a esta questão, recomendo a leitura dos artigos: «O Rei Stanislavski no tempo da modernidade: traduções, traições, omissões e opções», de Michel Mauch, Adriana Fernandes e Robson Corrêa de Camargo. Revista História e Estudos Culturais, setembro-dezembro de 2010, vol. 7, ano VII, n. 3 (em http://www.revistafenix.pro. br/PDF24/Dossie_03_Michel_Mauch.pdf). 
como potência para afetar e ser afetado. Nesta concepção, o corpo está sempre inacabado, pois encontra-se em permanente processo de renovação a partir da relação com outros corpos.

Seguindo por esta perspectiva, a noção de experiência, tal como ela vem nomeando certos efeitos da arte contemporânea, torna-se uma referência para pensar a possibilidade de renovação dos corpos em cena, colaborando neste esforço de atualização do «sistema» de Stanislávski. Na publicação organizada por Ana Kiffer, Renato Rezende e Christophe Bident, Experiência e arte contemporânea (2012), João Camillo Pena afirma ser a experiência o nome que se dá a «algo que excede a linguagem e o conceito, algo que sobra, que não pode ser contido e não tem onde caiba». Roberto Corrêa dos Santos destaca a potência criadora da experiência, uma vez ser aquilo que não se encontra no já feito, no conhecimento que dele pode ser extraído: «trata-se [...] de um ato que requer o desconhecer sempre, trata-se de estar solto no feito». Cassiano Quilici, nesse mesmo sentido, ao tratar da experiência da não-forma na atuação contemporânea, defenderá a necessidade do «desapego de qualquer noção de projeto, qualquer expectativa de resultados» (Quilici, 2015: 122). Do mesmo modo, Jorge Larrosa Bondía não define o sujeito da experiência «por sua atividade, mas por sua passividade, por sua receptividade, por sua disponibilidade, por sua abertura». Por isso, «é incapaz de experiência aquele que se põe, ou se opõe, ou se impõe, ou se propõe, mas não se “ex-põe” » (Bondía, 2002:25-26). A experiência, portanto, pode ser aqui compreendida como o que acontece em um corpo-ator quando afetado por intensidades não-discursivas e que, simultaneamente, reage psicofisicamente a essas intensidades em absoluta adequação com o sentido (ou com o sem-sentido) que ele dá ao que lhe acontece.

A pergunta que move Stanislávski, portanto, pode ser formulada da seguinte forma: como é possível fazer da atuação uma experiência? E como a literatura dramática pode fazer parte desse projeto? Stanislávski alerta para o risco que corre o ator quando busca a experiência por si mesmo, diretamente do texto. Insistir neste propósito, alerta o artista, só pode resultar na mais grosseira artificialidade.

Faça com a memória emocional e com os sentimentos reiterados o mesmo que o caçador faz com a caça - explicou A.N. - Se uma ave não voar ao encontro do caçador não há maneira de a encontrar no embrenhado da mata. Não há outro remédio se não atraí-la, fazendo com que saia da floresta, utilizando um apito especial, o chamado «chamariz». O nosso 
sentimento artístico é tão assustadiço como a ave florestal, e vive nos esconderijos da nossa alma. Se o sentimento não responder a partir dali, não o poderemos encontrar. Neste caso, temos que recorrer ao chamariz. (Stanislávski, 2018: 290)

Esta comparação esclarece as intenções últimas por trás de toda a pesquisa que culminou no «método» das ações físicas: despertar «o trabalho subconsciente da natureza através da psicotécnica consciente do ator» (ibidem, 40). Ou seja, Stanislávski apresenta a sua convicção de que a experiência só acontecerá a partir de uma estrutura muito bem elaborada e executada: a partitura de ações. A criação dessas ações, e sua criteriosa articulação numa sequência, faz da partitura a realização de uma composição própria do ator, que pode ser por ele repetida e sempre aperfeiçoada.

\section{ESTRATÉGIAS FUNDAMENTAIS PARA A CRIAÇÃO DA PARTITURA}

Se a partitura é uma composição, as ações físicas são o seu material. Grotowski, em sua palestra sobre Stanislávski realizada no Festival de Teatro de Santo Arcangelo (1988), procurou fazer o público compreender o que são as ações físicas a partir do que elas não são: atividades. Estas últimas seriam as ações quando se esgotam na mera referencialidade, como os exemplos por ele citados: limpar o chão, lavar os pratos, fumar cachimbo. Stanislávski também chamava a atenção para o risco desta confusão: a ação física é algo mais complexo, ela se realiza em cena e habita o «entre» o que o ator deseja fazer e o que o ator é levado a fazer. Em outras palavras: trata-se de um estado provocado pelo empenho do ator em interferir em uma situação e, simultaneamente, pelos impulsos reagentes às interferências que ele sofre desta mesma situação. A ação traz, então, um duplo aporte: é algo realizado pelo agente enquanto o agente se constitui

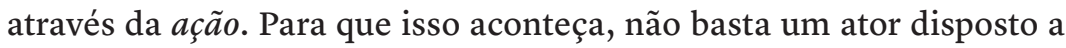
afetar, é preciso um ator que, enquanto afeta, deixa-se afetar.

As ações físicas estabelecem um campo ${ }^{6}$ de forças interativas e são por elas constituídas. Esse campo foi nomeado por Stanislávski como circunstância e sua produção a partir de uma obra da literatura dramática

6 A ideia de campo é tomada de empréstimo da física contemporânea por Umberto Eco (2010: 56) para tratar o que ele chama de obra aberta. O campo é «uma visão renovada das relações clássicas de causa e efeito unívoca e unidirecionalmente entendidas, implicando, pelo contrário, um complexo interagir de forças, uma constelação de eventos, um dinamismo de estrutura [...]». 
é um esforço que vai muito além do levantamento dos dados ficcionais propostos e sugeridos pelo dramaturgo. Ela depende também de uma posterior criação de condições para a circulação das forças. No relato de Toporkov sobre a aplicação do «método» das ações físicas no último estúdio organizado por Stanislávski, publicado com o título Stanislavski in rehearsal (Toporkov, 2008), especificamente nas memórias em torno do estudo de Tartufo, a criação das circunstâncias começa por uma análise do texto para ativar a imaginação dos atores. É possível perceber, mesmo quando ainda sentados em torno de uma mesa, que a exploração do texto foi feita de modo criativo e sensorial. Um trabalho ainda mental, mas não exclusivamente intelectual, uma vez que a imaginação do ator é convocada a todo momento a participar da análise, reagindo a estímulos extraídos do material literário.

A imaginação, assim como os demais elementos do «sistema», só tem a sua razão de ser quando integra e projeta fisicamente o ator na circunstância. Isso justifica a preocupação de Stanislávski na criação de tarefas físicas voltadas para a solução de problemas que estão inicialmente propostos ou sugeridos pela ficção. Toporkov conta que Stanislávski trabalhava incansavelmente sobre essas tarefas, algumas tão sutis e ricas em detalhes que o ator chegou a se espantar com o tempo de ensaio «perdido» em acontecimentos que sequer seriam percebidos pelo público. Um bom exemplo dessas tarefas nos é dado por Toporkov a partir dos ensaios do espetáculo The Embezzlers, de Valentin Kataev. Stanislávski estimulava o ator a criar o comportamento responsável e ordeiro da sua personagem, Vanechka, o caixa, explorando apenas a execução de pequenas tarefas:

Esta é a minha escrivaninha. Então, vamos torná-la absolutamente limpa. Aqui tem um grão de poeira e há um ponto, eu tentarei removê-los. Tente fazer isso com a máxima consciência. A mesa está solta, eu vou ter que firmá-la, torná-la firme. Preciso então encontrar algo para colocar debaixo dela. Acho um pedaço de madeira e coloco-o sob a perna. A escrivaninha não oscila mais e está nova em folha. Agora eu tenho que pôr todas as minhas coisas para fora em perfeita ordem. (Toporkov, 2008: 19-20)

Menos do que induzir o espectador e o ator à realidade ficcional, as minúcias e dificuldades que podem integrar uma tarefa têm como propósito oferecer meios de o ator manter-se empenhado na realização de algo que demanda esforço a fim de capturar sua atenção para o que se 
encontra fora de si. Uma atuação ensimesmada é sintoma de autoproteção por parte do ator para os riscos da criação. Essa atenção que se volta para si mesmo favorece o ator a acessar um «eu» e uma situação com os quais ele se identifica. Trata-se de um caminho estéril por determinar escolhas que estão condicionadas às expectativas que o ator acredita estarem sendo projetadas sobre ele pelos parceiros de trabalho, pelo encenador, pelos críticos, jurados, curadores, pela classe artística, pelo público, etc., aprisionando-o num comportamento social e profissional comportado, conformado e familiar.

Acrescenta-se à atenção demandada pelas tarefas outra importante função: a sua execução oferece a oportunidade para o ator observar-se passivamente, acompanhar com o devido distanciamento tudo o que lhe acontece. A atenção, portanto, é marcada por essa dualidade: ela é ativa, voltada para a realização da tarefa, e passiva, voltada para a observação e compreensão de uma constituição provisória, afetiva, inédita e inusitada de si mesmo.

A sequência de tarefas constitui uma linha de ação. Ela é ininterrupta e movida por um desejo comum a todas as tarefas alinhadas: o objetivo. Trata-se da apropriação por parte do ator de uma necessidade proposta ou sugerida originalmente pelo dramaturgo - ou por uma determinada perspectiva da circunstância proposta - à personagem literária. O conflito, enquanto categoria integrante das concepções tradicionais de drama, sempre localizará o problema no outro com quem o ator contracena. O outro é sempre força reagente, obstáculo. E o objetivo, por sua vez e em última instância, é o desejo de modificação desse outro - o que não deixa de ser um desejo de modificação de uma dada circunstância. $\mathrm{O}$ ator se torna agente e objeto da renovação, sendo as tarefas as estratégias pelas quais tal projeto é posto em campo.

Em sua tentativa de nomear os diferentes aspectos que envolvem a interferência mútua dos corpos em cena, Stanislávski cunhou os termos comunhão, irradiação e adaptação. São práticas que foram atualizadas por Grotowski como contato e que nesta investigação aparecem reunidas sob a ideia de relação: a disponibilidade para uma conexão sutil com a circunstância, (re)agindo no aqui e agora da atuação à imprevisibilidade do encontro. Em relação, os atores projetam no outro os seus desejos, esforçam-se para que o outro veja as imagens que lhes interessam, induzem o outro a pensar numa lógica que lhes é conveniente, ao mesmo tempo em que percebem e reagem às mesmas intenções que partem do sentido contrário. 
A relação é um investimento que se faz primordialmente entre os atores. Mas ela pode (e deve) ser estabelecida sobre objetos, espaço, e tudo mais em cena que possa resistir aos esforços de um ator, colaborando para a complexidade da tarefa. As concepções espaciais descendentes das propostas de Appia e Meyerhold, por exemplo, que exploram planos, escadas, praticáveis, estruturas, etc., podem ser aplicadas com esta finalidade. Pina Bausch também explorou a relação com materiais em suas obras. Como exemplo, cito o jogo complexo entre dançarinos e objetos integrantes da cenografia de Café Müller (1978), quando os artistas dançam, por vezes perigosamente, entre mesas e cadeiras que ambientam o café. Os objetos são empurrados e derrubados pelos próprios bailarinos enquanto dançam, gerando ao acaso diferentes configurações espaciais.

A criação e composição de uma linha de ação são determinadas pela sensibilidade e pelas referências próprias do ator em ação através do que Stanislávski chamou de se. Esse elemento do «sistema» determina que as escolhas e a execução das tarefas sejam respostas a uma simples pergunta: «O que eu (corpo-ator) faria "se" estivesse diante deste problema/obstáculo nestas circunstâncias (aqui e agora)?» Através do se, o ator se afasta da armadilha de um personagem/sujeito acabado, centrado e pressuposto, assim como se afasta de qualquer pressuposição a respeito si mesmo e da própria situação em que se encontra. Afinal, a pergunta não é feita àquele «eu» que o ator acredita ser, mas àqueles gerados a partir dos encontros nas circunstâncias.

Durante um período de improvisações, os atores amadurecem suas escolhas, detalham suas estratégias, sofisticam suas tarefas e ganham intimidade com o material. A linha de ações recebe o status de partitura quando alcança dois valores ambivalentes: execução rigorosa das ações e atualização permanente das ações. «Rigor» está relacionado com a atenção ativa do ator, voltada para a execução do objetivo e consequente realização precisa das tarefas em sua sequência, motivações, dinâmicas, ritmos, imagens, tensões, pontos de atenção, etc. A «actualização», por sua vez, está relacionada com a atenção passiva do ator, voltada para a percepção em si mesmo dos fenômenos mais sutis provocados pela circunstância. Atualizar uma partitura é estranhar o familiar, é estar sensível ao ineditismo de tudo que se repete, é se abrir para o desconhecer sempre.

A criação teatral a partir de matriz dramática vem sendo frequentemente rejeitada por quem não reconhece em suas categorias, situações, estrutura e personagens, a possibilidade de abarcar as dinâmicas do 
mundo contemporâneo, especificamente as de um sujeito que deseja se reconhecer em permanente inacabamento, assim como abarcar o teatro e a arte como renovação de perspectivas, lógicas e sensibilidades para os fatos que nos cercam. No entanto, como busquei demonstrar, as ações físicas de Stanislávski contrariam tal perspectiva por oferecerem estratégias de criação que permitem ao ator deslocar a noção de personagem dramática da representação de um sujeito outro para situá-la como os outros sujeitos de si, efeitos de uma situação sempre insólita, desconhecida, localizada entre a ficcionalidade dramatúrgica e a dramaturgia dos corpos em relação.

\section{REFERÊNCIAS BIBLIOGRÁFICAS}

BONDÍA, Jorge Larrosa (2002), «Notas sobre a experiência e o saber de experiência», in Revista Brasileira de Educação, n. ${ }^{\circ}$ 19, pp. 20-28, http://www.scielo.br/pdf/rbedu/n19/n19ao2.pdf.

BONFit to, Matteo (2013), Entre o ator e o performer, São Paulo, Perspectiva.

Deleuze, Gilles (2015), A lógica do sentido, 5. a ed., São Paulo, Perspectiva.

FOUCAUlt, Michel (2006), A hermenêutica do sujeito, São Paulo, Martins Fontes.

Grotovski, Jerzzy (2001), «Resposta a Stanislavski», in Revista Folhetim, Rio de Janeiro, Teatro do Pequeno Gesto, n. ${ }^{\circ}$ 9, pp. 3-21.

KIFFER, Ana, REZENDE, Ricardo e BIDENT, Christophe (orgs.) (2012), Experiência e arte contemporânea, Rio de Janeiro, Editora Circuito.

LEMos, Vitor (2016), Drama e subjetividade na atuação contemporânea: uma apropriação das ações físicas de Stanislávski, tese de doutorado, Pontifícia Universidade Católica do Rio de Janeiro.

Mот TA LIMA, Tatiana (2009), «Atenção, porosidade e vetorização: por onde anda o ator contemporâneo?», in Revista Subtexto, Belo Horizonte, ano 6, n. ${ }^{\circ}$ 6, pp. 27-35.

- (2015), «Conter o incontível: apontamentos sobre os conceitos de “estrutura” e "espontaneidade” em Grotowski», in Revista USP, São Paulo, 2 (2), pp. 47-66.

PICON-VAllin, Béatrice (2013), «Stanislavski e Meyerhold: solidão e revolta», in Revista Folhetim - Especial Stanislávski, Rio de Janeiro, Teatro do Pequeno Gesto e 7 Letras, n. ${ }^{3}$ o, pp. 6-33.

QUILICI, Cassiano Sydow (2015), «A experiência da Não Forma», in O ator-performer e as poéticas da transformação de si, São Paulo, Annablume, pp.117-123.

RICHARDS, Thomas (2012), Trabalhar com Grotowski sobre as ações físicas, São Paulo, Perspectiva.

STANislávs KI, Konstantin (2018), Preparação do Ator no seu processo criador de vivência das emoções [Diário de um discípulo], Lisboa, TNDMII e Bicho-do- Mato.

- (1970), A construção da personagem, Rio de Janeiro, Civilização Brasileira.

- (1984), A criação de um papel, 2.a edição, Rio de Janeiro, Civilização Brasileira.

TORPORKov, Vasili (2008), Stanislavski in Rehearsal, Londres, Methuen Drama.

VÁssiNA, Elena (2013), «Nenhum manual ou gramática de arte teatral: alguns apontamentos sobre a formação do sistema de Stanislávski», in Revista Folhetim - Especial Stanislávski, Rio de Janeiro, Teatro do Pequeno

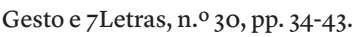

vÁssinA, Elena e LABAKI, Aimar (2015), Stanislávski: vida, obra e sistema, Rio de Janeiro, Funarte.

ZALtron, Michele Almeida (2016), O trabalho do ator sobre si mesmo segundo o «sistema» de K. Stanislávski, tese de doutorado, Universidade Federal do Estado do Rio de Janeiro. 


\section{VITOR LEMOS}

É actor, encenador e professor. Realizou o mestrado em Teatro na Universidade Federal do Estado Rio de Janeiro - UNIRIO (2000) e o doutoramento em Letras/Literatura, Cultura e Contemporaneidade na Pontifícia Universidade Católica do Rio de Janeiro - PUC-RJ (2016). Actualmente, leva a cabo investigação de pós-doutoramento no Centro de Estudos de Teatro da Universidade de Lisboa, com o título «A personagem como exercício da diferença: perspectivas para as ações físicas de Stanislávski». 